\title{
THE TEARS
}

BY

\section{FREDERICK RIDLEY}

A Meeting of the Royal Eye Hospital Clinical Society was held on Friday, January 14, 1944.

Mr. Holmes-Smith, the Chairman, said he had particularly been looking forward to Mr. Ridley's lecture-demonstration as he had found the important subject of the tears very cursorily dealt with in the text-books.

Mr. Frederick Ridley said that he was not surprised that the Chairman found it difficult to get succinct information about the tears. A great deal of research work had been done; but the results were scattered through the journals. He proposed in his, lecture to summarise some of the more salient points.

Much of the older work had been vitiated by faulty methods of collection of the tears, particularly by allowing evaporation of the collected fluid. This was why many. of the analyses gave far too high a figure for the sodium chloride.content, which was actually only 0.65 per cent. Tears were best collected in a hard glass, Wright's capsule, which sucked up the tears by capillarity. After collection of the tears the ends of the capsule could be sealed off in a bunsen flame. It was difficult to get enough unless a reflex. flow of secretion was provoked. This could easily be done by a drop of lemon juice on the caruncle, or by applying a tiny drop of absolute alcohol with an applicator.

Mr. Ridley emphasised the importance of the albumen and globulin content of the tears. These proteins were species-specific, and accounted for 0.669 per cent. Mr. Ridley boiled some tears in a small test-tube and pointed out that they coagulated. He shook up another small sample of tears, and they frothed. Both these demonstrations depended on the protein content of the tears.

This protein content was important too for purposes of surface tension. There was not really a cornea-air interface as we tended to let ourselves suppose. It was really a tears-air interface; and for the maintenance of an adequate surface tension in this thin film the protein was essential. Its presence also affected the permeability of the cornea to drugs.

What was the best vehicle in which we could apply drugs to the eye so that they would quickly and efficiently penetrate the cornea in adequate concentration? Dr. Miklos Klein had shewed that the ordinary ointment vehicles produced an aqueous solution of the contained drug in the form of a simple mixture or an emulsion in which the outer emulsion phase was oily. Clearly a true emulsion should be formed, not a mixture which is imperfect and tends to separate out, and the emulsion should not imprison the water dissolved drug in an impermeable oity coating. Klein had pointed 
out that mono-glyceryl-stearate, available commercially as Tegin, formed true emulsions of the right type, was non-irritant and could be autoclaved without destroying either the base or the emulsion. It can be preserved indefinitely by a preservative such as 0.1 per cent. nipagin.

Lysozyme was a constituent of the tears of the greatest clinical and theoretical importance. Mr. Ridley recounted how it had been discovered by Prof. Fleming in much the same way as had Penicillin. When plating out sputum the plate was accidentally contaminated with a colony of M.lysodeicticus. Fleming noticed that the colony did not grow on to the sputum covered part of the plate but was sharply cut off. Investigation shewed this was because the sputum contained lysozyme, a bacterial inhibitor capable of acting in high dilution, but destroyed by heat. Lysozyme was present in tears, saliva, sputum, skin, and in the leucocytes. Our domestic chickens eggs would all addle if egg white did not contain a high concentration of lysozyme.

Lysozyme rapidly became ineffective below a certain fairly critical dilution for each sensitive organism. Thus M. lysodeicticus, the most sensitive of all bacteria is dissolved at $37^{\circ} \mathrm{C}$. in a dilution of one in five million tears, in twenty-four hours. Plates were shown in which the growth of recently isolated strains of staphylococcus and hæmolytic streptococcus were completelý inhibited by concentrations of $1 / 5$ and $4 / 5$ tears-saline dilutions respectively. He drew attention particularly to the fact that the streptococci grew freely when the dilution was equal to $3 / 5$ tears-saline. Normal tears are very effective against even virulent organisms but there is not much margin. Epiphora lasting a few hours produces a reduction of lysozyme titre down to as little as 25 per cent. and then any bacteria in the area grow out and conjunctivitis and keratitis result. By repeated estimations in a series of cases it had been possible to compare the lysozyme titre of normal tears with that of tears in various inflammatory conditions of the eye. It was found consistently that the lysozyme was reduced below 60 per cent. in the active infective stage and that recovery was associated with a recovery to 75 per cent. titre or better. General causes, natably congenital syphilis, are often associated with a chronic deficiency in lysozyme.

Mr. Ridley then discussed the subject of atropine irritation. This was described by von Graefe ; but was for many years uninvestigated. The condition occurred in both sexes, at all ages. Dermatitis from atropine had been 'reported as reaching as far as the umbilicus in an atropine sensitive patient. Atropine irritation was seldom seen in an uncongested eye and never occurred at the first instillation of the drug.

Waller had done useful pioneer work in which he suggested the irritant was a compound of atropine and tears protein. Later 
research rather incriminated the protein from the conjunctival goblet cells.

Mr. Ridley divided patients with atropine irritation into two sub. groups. In the larger group the patients were only sensitive to higher concentrations of atropine, which caused chemical irritation. They were not sensitive to $1 / 800$ atropine, so were readily treated by reducing the dilution. Most of them could tolerate atropine gr. 1/250 in lamellar form, or dilution of hyoscine 1/400.

The smaller group consisted of genuinely allergic patients in whom the atropine-protein compound acted as an antigen. These people could be desensitised by graded serum-atropine injections in about 10 days; but only to weak dilutions of atropine. They could not tolerate the chemical irritation of stronger solutions of atropine above $1 / 800$.

In parenthesis $\mathrm{Mr}$. Ridley mentioned that atropine drops exercise a local inhibition on the secretory activity of the lacrimal gland. This was important in eyes in which the lysozyme was lowered by prolonged lacrimation. The administration of atropine could lessen the watering, so that the tears would increase in their lysozyme titre, and recovery was thus hastened.

In the administration of drugs to the eye the influence of their dilution by the tears must not be forgotten. Most drops were diluted beyond useful value in 6 minutes. Zinc drops of course had a specific action in angular conjunctivitis. He thought irrigations by $1 / 1000$ silver nitrate were of value, as also were argyrol and protargol. Mercurials, eusol, and copper salt solutions had a - negligible value in therapeutic concentrations. Albucid solutions were rapidly diluted. Drugs such as fluorescein were absorbed by the tissue surfaces, and so had a longer effective action period.

In the subsequent discussion :-

Professor Sorsby asked whether the secretion of tears was in any way affected by the extent of the patient's saturation with vitamins. He showed a case of Sjogren's sydrome of kerato-conjunctivitis sicca from lack of tear secretion. The lacrimal secretion had appeared to increase after the administration of ascorbic acid. Conversely in this particular case the patient had developed his first symptoms of the associated arthritis while the vitamin was being administered.

Mr. Savin thanked the lecturer for a most instructive evening.

At Horton, Mr. Lumley had obtained excellent results with hypopyon ulcer by the hourly instillation of 30 per cent. albucid drops. - That seemed extraordinary if they were diluted below effective strength in six minutes. He had been impressed by Mr. Ridley's advocacy of an oil-in-water emulsion as a vehicle for the administration of atropine. What strength atropine did Mr. Ridley employ for routine work in children?

Mr. Goldsmith said the lecturer had mentioned lysozyme in egg-white, besides tears, sputum, and saliva. Had egg-white any therapeutic value in drop form ? He also asked whether the use of an oil-in-water emulsion might increase the general absorption of the contained atropine, and so the liability to general toxic symptoms ?

$M$ iss Lingfield described a case in which a child had developed atropine irritation after atropine had been instilled in a perfectly white eye. As far as she knew the child had never been previously sensitised to atropine

In reply Mr. Ridley said be was not aware of any vitamin association with the secretion of tears having been described. Xerophthalmia occurs in rats 
deprived of vitamin $\mathrm{A}$ as had been described by Findlay. He had also observed a great reduction in tears protein in such a case on one occasion. He agreed with Mr. Savin that Mr. Lumley had had excellent results with albucid 30 per cent. applied hourly: He attributed this to the strength used and to the frequent application. He had not wished to imply that albucid was useless but to draw attention to the fact that in the concentrations commonly used and infrequently applied it could have no useful action in view of its rapid dilution and the delay of several hours before it began to act effectively. He himself used 1 per cent. atropine for refraction work and thought that less than this strength was inadequate as a cycloplegic in children. He deprecated the routine use of 1 per cent. atropine in treatment when a less concentration would very often suffice. If only $\frac{1}{2}$ per cent. atropine were used as a routine the number of cases of irritation would be reduced to about one quarter. If lamellae were used only the allergic group-about 10 per cent. would remain. He drew attention to the fact that a suspected case could be assessed by the simple patch test he had described and the use of an irritating streng th of mydriatic avoided.

In reply to $\mathrm{Mr}$. Goldsmith he said that there was no risk of increased toxicity if oil-in-water emulsions were used, the high concentration of the drug in the restricted water phase increased its efficacy but was offset, as regards toxicity, by the small amount of total drug administered. Egg-white drops might be useful, but many patients would develop sensitisation to egg albumen. Also the concentration of lysozyme was not much higher in egg white than in normal tears, one should concentrate on the restoration of a normal titre in the tears. He said there was no case reported in which irritation had developed to a first drop of atropine and theoretically it should be impossible. He had not seen irritation develop in the routine use of atropine for refraction in children.

\section{ABSTRACTS}

\section{MISCELLANEOUS}

(1) Vail, Derrick and Ascher, K. W. (Cincinnati).-Corneal vascularisation problems. Amer. $\mathrm{Jl}$. of Ophthal., p. 1025, October, 1943.

(1) In a comprehensive paper the authors show that as long as definite pathological corneal processes are absent corneal vascularization never takes place and even very intensive engorgement does not suffice for trespassing upon the anatomically preformed limbal meshwork. Any kind of long-standing engorgement in conjunctival vessels may open up pre-existing narrower vessels or collaterals, but neovascularization of the normally clear cornea does not occur in the absence of corneal disease or involvement in disease.

A. F. macCallan.

(2) Haycraft, G. F. (Wolverhamp̀ton).-Amblyopia ex anopsia. - Middlemore Lecture, 1943.

(2) Haycraft gave the Middlemore Lecture in 1943 with the above title, with special reference to recruitment for the Armed 